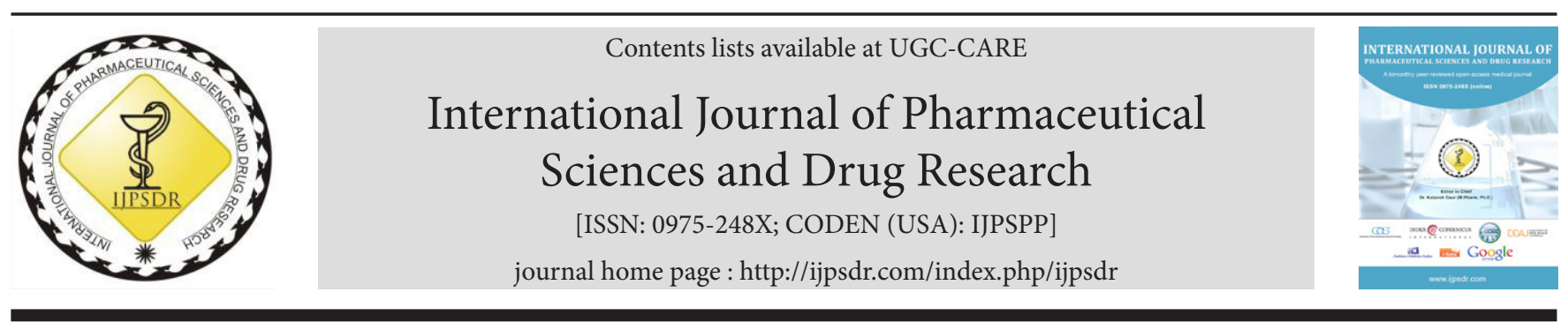

Research Article

\title{
Design and Evaluation of Lovastatin Solid Dispersions Incorporated Trilayer Matrix Tablets
}

\author{
Chinthala Shanthi Priya*, Tummaluru Ramamohan Reddy
}

Department of Pharmacy, Mewar University, Chittorgarh-312901, Rajasthan, India

\begin{tabular}{l} 
A R T I C L E I N F O \\
\hline Article history: \\
Received: 16 April, 2020 \\
Revised: 18 June, 2020 \\
Accepted: 26 June, 2020 \\
Published: 30 July, 2020 \\
Keywords: \\
HMG-CoA reductase inhibitors, \\
Kolliphor ELP, \\
Lovastatin, \\
Solid dispersions, \\
Trilayer matrix tablets. \\
D0I: \\
10.25004/IJPSDR.2020.120409
\end{tabular}

\section{INTRODUCTION}

Biopharmaceutical classification (BCS) class II drugs exhibit fever solubility and inferior dissolution rates, which lead to insufficient drug bioavailability. ${ }^{[1]}$ The bioavailability and dissolution of these drugs in gastro intestinal (GI) tract are enhanced by incorporating techniques, like micronization,

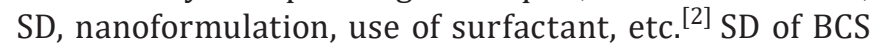
class II drugs is proven technique for potential enhancement of dissolution of hydrophobic drugs. ${ }^{[3]}$ SD is defined as dosage form in which the drug is dispersed in pharmacologically inert matrix with an objective of attaining enhanced

\begin{abstract}
A B S T R A C T
The current work is aimed to design, prepare, and evaluate the trilayer matrix tablets incorporated with lovastatin solid dispersion (SD) for extending drug release. The lovastatin SD prepared by using the solvent evaporation technique with varying amounts of polymers (GMS II, soluplus, kolliphor ELP, PEG 2000, and urea) for enhancing the drug solubility. All the formulations examined for physicochemical parameters are within the permissible limits. The optimized SD formulation was incorporated into trilayer matrix tablets, which were prepared using different polymers (HPMC 15M and K100M, chitosan, and xanthan gum) by direct compression method for sustaining the drug release. The drug dissolution of optimized lovastatin SD formulation SD15 (drug, soluplus, and SLN) was $99.88 \pm 5.32 \%$ within 60 minutes, which is higher than pure drug $47.33 \pm 2.25 \%$ and other formulations. The Fourier transform infrared (FTIR), X-ray diffraction (XRD), and scanning electron microscope (SEM) data, assure the compatibility of drug and excipients and amorphous nature of lovastatin. The SDs were further incorporated into trilayer matrix tablets with active layer and barrier layers. Eight formulations of lovastatin trilayer matrix tablets (AF9-HF9) designed and checked for pre-compression parameters. Formulation GF9 demonstrated the highest drug release of $99.41 \pm 5.28 \%$ for 24 hours sustainably over an extended period of time and excellent flow properties. The release order kinetics data indicate the zero-order release with the highest $\mathrm{R}^{2}$ of 0.9957 for GF9, superior to market extended-release formulation $\left(R^{2}=0.9934\right)$. All the formulations showed the best fit to the Higuchi model and Korsmeyer-Peppa's model, indicating diffusion and non-Fickian diffusion process of drug release. GF90 was found to be stable for 180 days at accelerated conditions. Hence, the solubility and dissolution rate of lovastatin was enhanced by the SD technique further incorporated into trilayer matrix tablets for sustainable, extended drug release up to 24 hours.
\end{abstract}

bioavailability ${ }^{[4]}$ via increase in wettability or reduction in particle size or by conversion of crystalline form of drug to amorphous. ${ }^{[5]}$ Lovastatin is a cholesterol-lowering agent that belongs to the class of medications called statins. It was the second agent of this class discovered. Lovastatin is a competitive inhibitor of $\beta$-hydroxy $\beta$-methylglutaryl-CoA (HMG-CoA) reductase with a binding affinity 20,000 times greater than HMG-CoA. The main objectives of the study are to enrich the solubility, dissolution rates of lovastatin by SD technique, and incorporate into trilayer matrix tablets for extended drug release up to 24 hours.

\footnotetext{
${ }^{*}$ Corresponding Author: Chinthala Shanthi Priya

Address: Department of Pharmacy, Mewar University, Chittorgarh-312901, Rajasthan, India

Email $\bowtie$ : shanthipriyapharma@gmail.com

Tel.: +91-9502490989

Relevant conflicts of interest/financial disclosures: The authors declare that the research was conducted in the absence of any commercial or financial relationships that could be construed as a potential conflict of interest.

Copyright (c) 2020 Chinthala Shanthi Priya et al. This is an open access article distributed under the terms of the Creative Commons AttributionNonCommercial-ShareAlike 4.0 International License which allows others to remix, tweak, and build upon the work non-commercially, as long as the author is credited and the new creations are licensed under the identical terms.
} 


\section{MATERIALS AND METHODS}

\section{Materials}

Lovastatin was kindly gifted by Aurobindo Pharma Ltd., Hyderabad. Urea, soluplus, PEG 2000, kolliphor ELP, kolliwax GMS II, sodium lauryl sulphate (SLS), methanol, hydroxypropyl methylcellulose (HPMC) K 15 M, chitosan, xanthan gum, $\mathrm{CaHPO}_{4}, \mathrm{C}_{36} \mathrm{H}_{70} \mathrm{MgO}_{4}$, and talc purchased from Corel Pharma Chem, Ahmedabad, Gujarat, India. Altoprev ${ }^{\circledR}$ (lovastatin extended-release tablet marketed formulation) purchased from the local market.

\section{Methods}

\section{Preliminary Solubility Studies of Lovastatin}

Excess lovastatin stirred with $25 \mathrm{~mL}$ of carriers crospovidone, croscarmellose, eudragit, labrafac PG, kolliwax RH 40, GMS II, soluplus, kolliphor ELP, PEG 2000, and urea for 24 hours. The suspension clarified through a Whatman filter paper no. 1, and the filtered solution diluted with methanol for spectrophotometric analysis of drugs at UV $238 \mathrm{~nm}^{[6]}$

\section{Preparation of Lovastatin SD}

The weighed amount of lovastatin and polymers (urea, PEG 2000, koluplus, kolliwax GMS II, and kolliphor ELP) along with SLS are combined in varying drug-polymersurfactant ratios $(1: 1: 1,1: 2: 1.5$, and 1:3:2). Fifteen lovastatin SD formulations were formulated by the solvent evaporation method (Table 1) by dissolving the mixture in methanol followed by evaporation to dryness. The solid, thus, obtained is powdered and passed through a sieve for further investigation. ${ }^{[7]}$

\section{Evaluation of Lovastatin SDs}

Solubility studies of lovastatin SD performed as per the published method. ${ }^{[8]}$ The percentage practical yield ${ }^{[9]}$ and $\%$ drug content ${ }^{[10,11]}$ were evaluated as per the referred methods. The dispersions are further characterized for FTIR spectroscopic analysis, ${ }^{[12]}$ XRD, ${ }^{[13,14]}$ and SEM studies $^{[15]}$ for drug compatibility studies.

In vitro Drug Dissolution of Lovastatin $S D$

The dissolution of lovastatin from SDs containing $180 \mathrm{mg}$ of drug was investigated in $900 \mathrm{~mL}$ phosphate buffer (pH 6.8) using USP type II (paddle type) dissolution test apparatus, and the samples were analyzed at different time intervals at $238 \mathrm{~nm} .{ }^{[16]}$

\section{Stability Studies}

The lovastatin SD was sealed in 40 cc HDPE container under controlled conditions in the stability chamber (Thermo Lab, India) at $75 \pm 5 \% \mathrm{RH}$ and $40 \pm 2^{\circ} \mathrm{C}$. Samples analyzed for 1,2 , and 3 months for $\%$ drug content and drug dissolution rates. ${ }^{[17]}$

\section{Formulation of Lovastatin Trilayer Tablets}

Pre-compression parameters: The angle of repose, Carr's compressibility index, bulk density, tapped density, ${ }^{[18]}$ and Hausner's ratio ${ }^{[19]}$ evaluated, as per referred procedures.

\section{Formulation of Lovastatin Trilayer Matrix Tablets}

The trilayered matrix tablets of lovastatin were prepared by the direct compression method. The first step in the formulation was to develop the middle active layer so as to give at least $90 \%$ drug release for 12 hours. The release profile of this layer might not be of constant rate type but

Table 1: Composition of lovastatin SDs

\begin{tabular}{lllllllll}
\hline $\begin{array}{l}\text { Ingredients } \\
\text { formulation ratios }\end{array}$ & Lovastatin $(\mathrm{mg})$ & Urea $(\mathrm{mg})$ & $\begin{array}{l}\text { PEG 2000 } \\
(\mathrm{mg})\end{array}$ & $\begin{array}{l}\text { Kolliphor ELP } \\
(\mathrm{mg})\end{array}$ & $\begin{array}{l}\text { Kolliwax GMS } \\
\text { II }(\mathrm{mg})\end{array}$ & $\begin{array}{l}\text { Soluplus } \\
(\mathrm{mg})\end{array}$ & $\begin{array}{l}\text { SLS } \\
(\mathrm{mg})\end{array}$ & $\begin{array}{l}\text { Methanol } \\
(\mathrm{mL})\end{array}$ \\
\hline SD1 1:1:0.5 & 40 & 40 & - & - & - & - & 20 & Qs \\
SD2 1:1.5:1 & 40 & 60 & - & - & - & - & 40 & Qs \\
SD3 1:2:1.5 & 40 & 80 & - & - & - & - & 60 & Qs \\
SD4 1:1:0.5 & 40 & - & 40 & - & - & - & 20 & Qs \\
SD5 1:1:5:1 & 40 & - & 60 & - & - & - & 40 & Qs \\
SD6 1:2:1.5 & 40 & - & 80 & - & - & - & 60 & Qs \\
SD7 1:1:0.5 & 40 & - & - & 40 & - & - & 20 & Qs \\
SD8 1:1.5:1 & 40 & - & - & 60 & - & - & 40 & Qs \\
SD9 1:2:1.5 & 40 & - & - & 80 & - & - & 60 & Qs \\
SD10 1:1:0.5 & 40 & - & - & - & 40 & - & 20 & Qs \\
SD11 1:1.5:1 & 40 & - & - & - & 60 & - & 40 & Qs \\
SD12 1:2:1.5 & 40 & - & - & - & 80 & - & 60 & Qs \\
SD13 1:1:0.5 & 40 & - & - & - & - & 40 & 20 & Qs \\
SD14 1:1.5:1 & 40 & - & - & - & - & 60 & 40 & Qs \\
SD15 1:2:1.5 & 40 & - & - & - & - & 80 & 60 & Qs \\
\hline
\end{tabular}


would be preferable of constantly falling rate type. This layer would then be sandwiched between barrier layers (upper and lower layers) so as to continue the drug release for 24 hours. $^{[20]}$

\section{Formulation of Active Layer}

Ten formulations (F1-F10) designed with varying grades of polymers [HPMC 15M, K100M, chitosan, and xanthan gum] along with lovastatin (180 mg), talc $(1.5 \mathrm{mg})$, and magnesium stearate $(1.5 \mathrm{mg})$. The formulations sieved through \#60 and compressed to $12 \mathrm{~mm}$ diameter flat punches (Table 2). ${ }^{[20]}$

\section{In vitro Drug Release Studies of Lovastatin Active Layer (F1-F10) Tablets}

The dissolution test apparatus, USP 2 (paddle method), was used for conducting in vitro drug dissolution of lovastatin by employing Shimadzu UV-visible spectrophotometer at $238 \mathrm{~nm}$ with $900 \mathrm{~mL}$ phosphate buffer (pH 6.8) as dissolution medium and the samples were analyzed at different time intervals at $238 \mathrm{~nm} .{ }^{[21]}$

\section{Preparation of Barrier Layer}

The barrier layer formulated using various polymers, as shown in Table 3, followed by compressing the mixture by employing rotary press (Table 3 ). ${ }^{[22]}$

\section{Formulation of Lovastatin Trilayer Matrix Tablets}

The direct compression method is chosen for preparation of lovastatin trilayer polymer matrix tablets. Initial studies conducted to optimize the active layer composition for maximum extended drug release. This layer is then sandwiched within barrier layers for 24 hours continued release of drugs. Xanthan gum, along with other suitable excipients compressed with $40 \mathrm{mg} /$ tablet, forms the matrix. Weighed amount of active and barrier layer powders are mixed thoroughly for 20 minutes. The volume of $12 \mathrm{~mm}$ round die cavity is adjusted to weight equivalent to $350 \mathrm{mg}$ of matrix tablet. The powder weight equivalent to $100 \mathrm{mg}$ of bottom layer is spread in die cavity and compressed. The middle layer carrying $180 \mathrm{mg}$ of drug is spread over top layer, followed by compression to obtain a lovastatin trilayer matrix tablet (Table 4). ${ }^{[23]}$

\section{Evaluation of Lovastatin Trilayer Tablets}

The tablets are evaluated for weight variation, hardness, and friability conducted as per the methods established. The drug content is estimated by dissolving $10 \mathrm{mg}$ of drug in $50 \mathrm{~mL}$ water analyzed at $238 \mathrm{~nm}$ by a UV-visible spectrophotometer. The formulations were also evaluated for micrometric study of densities, angle of response, and Carr's index. ${ }^{[24]}$

\section{In vitro Drug Release Studies}

The dissolution test apparatus, USP 2 (paddle method), was used for conducting in vitro drug dissolution studies using Shimadzu UV-visible spectrophotometer with $900 \mathrm{~mL}$ phosphate buffer ( $\mathrm{pH}$ 6.8) as dissolution medium, and the samples were analyzed at different time intervals at $238 \mathrm{~nm}$.

\section{Drug Release Kinetics}

To describe the kinetics of the drug release from matrix tablet, mathematical models, such as, zero-order, firstorder, and Higuchi models were used. The criterion for selecting the most appropriate model was chosen on the basis of the goodness or fit test. ${ }^{[25]}$

Table 2: Formulation trails for active layer (F1-F10) of lovastatin

\begin{tabular}{|c|c|c|c|c|c|c|c|c|c|c|}
\hline Ingredients (mg) & $F 1$ & $F 2$ & F3 & $F 4$ & F5 & F6 & F7 & F8 & F9 & F10 \\
\hline Lovastatin SDs & 180 & 180 & 180 & 180 & 180 & 180 & 180 & 180 & 180 & 180 \\
\hline HPMC K 15 M & 40 & 45 & 50 & 55 & 60 & - & - & - & - & - \\
\hline HPMC K 100 M & - & - & - & - & - & 40 & 50 & 60 & 70 & 80 \\
\hline Chitosan & 40 & 40 & 30 & 65 & 60 & 55 & 50 & 45 & 40 & 35 \\
\hline Xanthan gum & - & - & - & - & - & - & 30 & 35 & 50 & 40 \\
\hline Dibasic calcium phosphate & 37 & 32 & 37 & 32 & 27 & 72 & 37 & 27 & 7 & 12 \\
\hline Magnesium stearate & 1.5 & 1.5 & 1.5 & 1.5 & 1.5 & 1.5 & 1.5 & 1.5 & 1.5 & 1.5 \\
\hline Talc & 1.5 & 1.5 & 1.5 & 1.5 & 1.5 & 1.5 & 1.5 & 1.5 & 1.5 & 1.5 \\
\hline Total weight (mg) & 300 & 300 & 300 & 300 & 300 & 300 & 300 & 300 & 300 & 300 \\
\hline \multicolumn{11}{|c|}{ Table 3: Formulation trails of barrier layer } \\
\hline Ingredients (mg) & & $A$ & $B$ & $C$ & & $D$ & $E$ & $F$ & $G$ & $H$ \\
\hline Sodium CMC & & 15 & 20 & 25 & & 30 & 35 & 40 & 42 & 45 \\
\hline Xanthan gum & & 22 & 24 & 22 & & 18 & 20 & 15 & 15 & 15 \\
\hline Ethyl cellulose & & 25 & 25 & 25 & & 25 & 25 & 25 & 25 & 25 \\
\hline Dibasic calcium phosphate & & 35 & 28 & 25 & & 24 & 17 & 17 & 15 & 12 \\
\hline Total weight (mg) & & 100 & 100 & 100 & & 100 & 100 & 100 & 100 & 100 \\
\hline
\end{tabular}

${ }^{*} \mathrm{Mg}$. stearate and talc was added $1.5 \mathrm{mg}$ each in all formulations 
Chinthala Shanthi Priya et al.

Table 4: Trilayer tablet formulation trails

\begin{tabular}{|c|c|c|c|c|c|c|c|c|}
\hline Ingredients (mg) & $A F 9$ & $B F 9$ & CF9 & DF9 & EF9 & FF9 & GF9 & HF9 \\
\hline \multicolumn{9}{|c|}{ Active layer (F9) (total wt 300 mg) } \\
\hline Lovastatin SD & 180 & 180 & 180 & 180 & 180 & 180 & 180 & 180 \\
\hline HPMC K 15 M & - & - & - & - & - & - & - & - \\
\hline HPMC K100 M & 70 & 70 & 70 & 70 & 70 & 70 & 70 & 70 \\
\hline Chitosan & 40 & 40 & 40 & 40 & 40 & 40 & 40 & 40 \\
\hline Xanthan gum & 50 & 50 & 50 & 50 & 50 & 50 & 50 & 50 \\
\hline Dibasic calcium phosphate & 7 & 7 & 7 & 7 & 7 & 7 & 7 & 7 \\
\hline Magnesium stearate & 1.5 & 1.5 & 1.5 & 1.5 & 1.5 & 1.5 & 1.5 & 1.5 \\
\hline Talc & 1.5 & 1.5 & 1.5 & 1.5 & 1.5 & 1.5 & 1.5 & 1.5 \\
\hline \multicolumn{9}{|c|}{ Barrier layer (total wt $100 \mathrm{mg}$ ) } \\
\hline Sodium CMC & 15 & 20 & 25 & 30 & 35 & 40 & 42 & 45 \\
\hline Xanthan gum & 22 & 24 & 22 & 18 & 20 & 15 & 15 & 15 \\
\hline Ethyl cellulose & 25 & 25 & 25 & 25 & 25 & 25 & 25 & 25 \\
\hline Dibasic calcium phosphate & 35 & 28 & 25 & 24 & 17 & 17 & 15 & 12 \\
\hline Magnesium stearate & 1.5 & 1.5 & 1.5 & 1.5 & 1.5 & 1.5 & 1.5 & 1.5 \\
\hline Talc & 1.5 & 1.5 & 1.5 & 1.5 & 1.5 & 1.5 & 1.5 & 1.5 \\
\hline
\end{tabular}

\section{Stability Data}

The drug layered pellets subjected to stability study in REMI make stability chamber and studied at $40^{\circ} \mathrm{C} / 75 \%$ $\mathrm{RH}$ for $\%$ drug content and $\%$ drug release for 6 months. ${ }^{[26]}$

\section{RESULTS}

\section{Solubility Data of Lovastatin Physical Mixture}

The mixture of lovastatin and soluplus exhibited higher solubility of $2.79 \pm 0.52 \mathrm{mg} / \mathrm{mL}$, i. e., 25 -fold higher than lovastatin. The polymers PEG2000, crospovidone, kolliphor ELP, croscarmellose, eudragit, kolliwax GMS II, labrafac PG, urea, and kolliwax RH 40 exhibited lower solubility, hence, not considered for SD formulation (Fig. 1).

\section{Preparation of Lovastatin SD}

Total 15 lovastatin SD formulations prepared by solvent evaporation method comprising urea, PEG 2000, kolliphor ELP, kolliwax GMS II, soluplus, and SLS in varying amounts of 1:1:0.5, 1:1.5:1, and 1:2:1.5. (Fig. 2; Table 1), and all the formulations are free-flowing powders.

\section{Solubility of Lovastatin SD}

The formulation (SD 15) containing lovastatin, soluplus, and SLS (1:2:1.5) exhibited higher solubility of $5.993 \pm 0.04 \mathrm{mg} / \mathrm{mL}$, than pure drug ( $0.186 \pm 0.09 \mathrm{mg} / \mathrm{mL})$ (Fig. 3).

\section{\% Practical Yield (PPY) and Drug Content}

The PPY for all SD formulations lies within $90.21 \pm 0.05 \%$ to $98.36 \pm 0.25 \%$ with maximum yield of $98.36 \pm 0.25 \%$ for formulation SD15 (Table 5).

The drug content of all SD formulations ranges between $0.42 \pm 0.05$ and $99.12 \pm 0.45 \%$ with maximum value of $99.12 \pm 0.45 \%$ for SD 15 (Table 5).

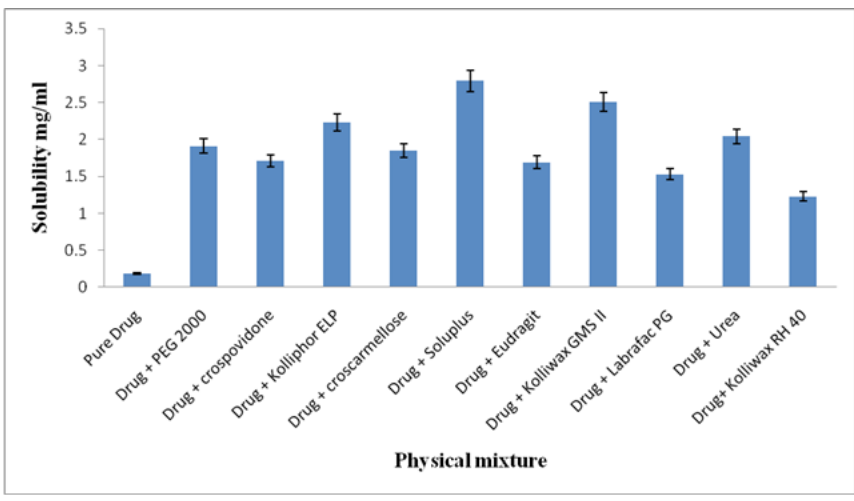

Fig. 1: Preliminary solubility studies of lovastatin physical mixture $\mathrm{n}=3( \pm \mathrm{SD})$

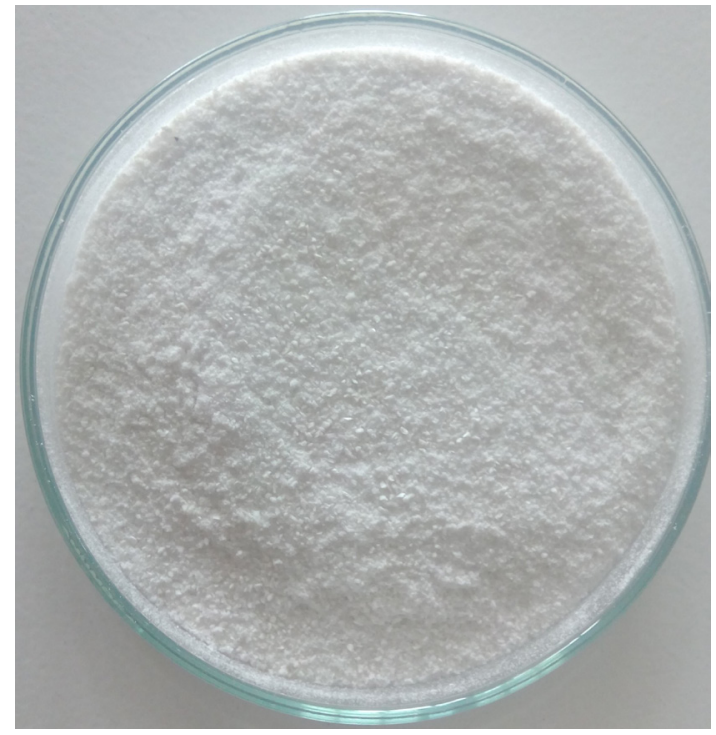

Fig. 2: Lovastatin optimized SD formulations 
Table 5: PPY and drug content for lovastatin SD

\begin{tabular}{llll}
\hline S. No. & Lovastatin SDs & $P P Y$ & \% drug content \\
\hline 1 & SD1 & $90.88 \pm 0.12$ & $94.36 \pm 0.3$ \\
2 & SD2 & $94.18 \pm 0.22$ & $90.45 \pm 0.2$ \\
3 & SD3 & $95.36 \pm 0.24$ & $95.67 \pm 0.35$ \\
4 & SD4 & $91.37 \pm 0.15$ & $92.47 \pm 0.05$ \\
5 & SD5 & $93.28 \pm 0.2$ & $96.37 \pm 0.35$ \\
6 & SD6 & $96.27 \pm 0.26$ & $93.45 \pm 0.3$ \\
7 & SD7 & $95.66 \pm 0.24$ & $91.27 \pm 0.25$ \\
8 & SD8 & $94.37 \pm 0.22$ & $95.38 \pm 0.35$ \\
9 & SD9 & $92.37 \pm 0.18$ & $90.45 \pm 0.2$ \\
10 & SD10 & $90.98 \pm 0.12$ & $97.66 \pm 0.35$ \\
11 & SD11 & $93.27 \pm 0.2$ & $92.38 \pm 0.25$ \\
12 & SD12 & $96.74 \pm 0.26$ & $95.68 \pm 0.35$ \\
13 & SD13 & $92.67 \pm 0.18$ & $92.45 \pm 0.25$ \\
14 & SD14 & $93.45 \pm 0.2$ & $95.45 \pm 0.35$ \\
15 & SD15 & $98.36 \pm 0.3$ & $99.12 \pm 0.45$ \\
\hline $\mathrm{n}=3( \pm S D)$ & &
\end{tabular}

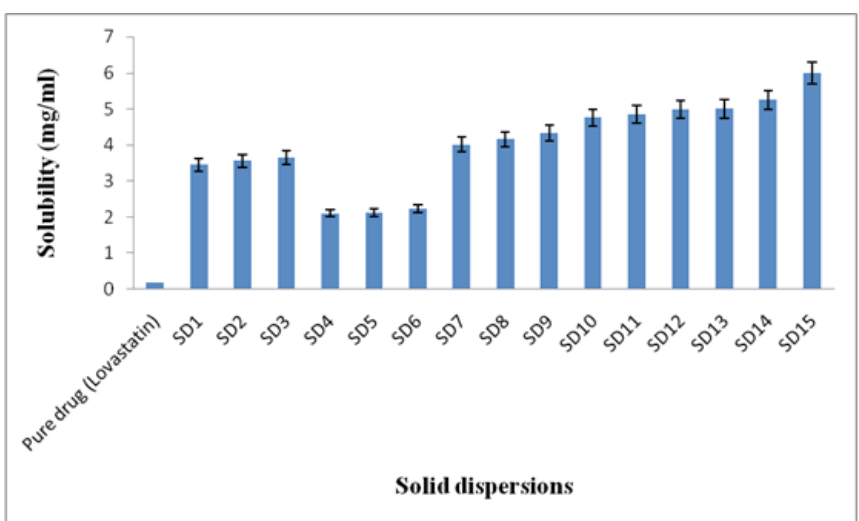

Fig. 3: Solubility of lovastatin SD; $n=3( \pm S D)$

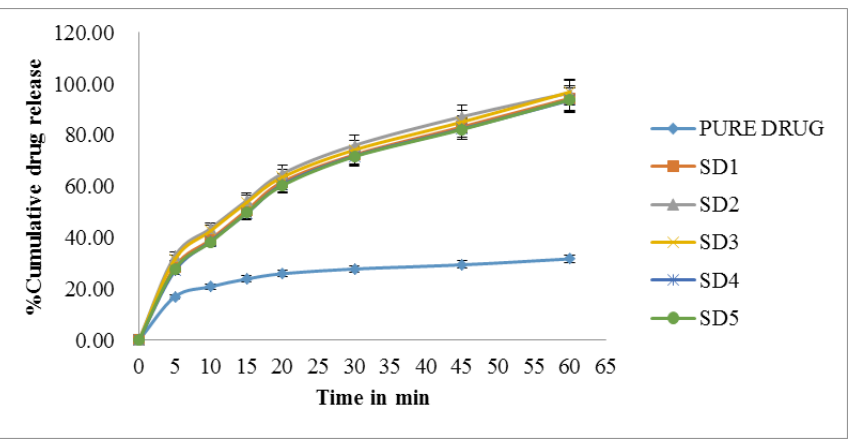

Fig. 4: Dissolution of pure drug and SD1 to SD5; $\mathrm{n}=3( \pm \mathrm{SD})$

\section{In vitro Drug Dissolution Studies}

The dissolution studies indicate marked increase in drug dissolution rate of lovastatin SD in comparison to lovastatin pure drug. Formulation SD15 containing drug, soluplus, and SLS in 1:2:1.5 ratio, shown higher dissolution rate, i.e., $99.88 \pm 5.32 \%$ (Figs 4 to 6 ).

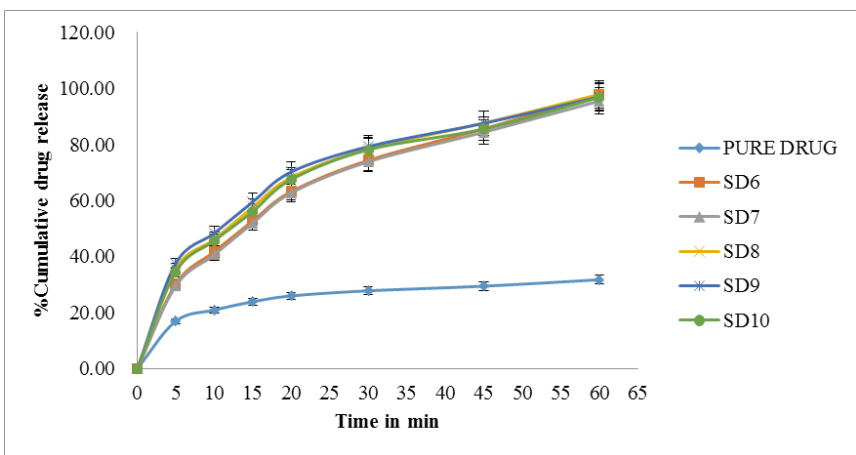

Fig. 5: Dissolution of pure drug and SD6 to SD10; $n=3( \pm S D)$

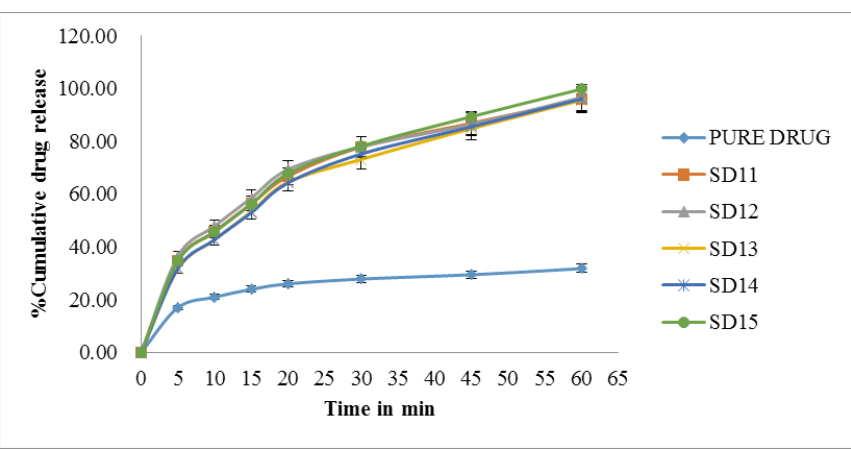

Fig. 6: Dissolution profile of pure drug and SD11 to SD15; $\mathrm{n}=3( \pm \mathrm{SD})$

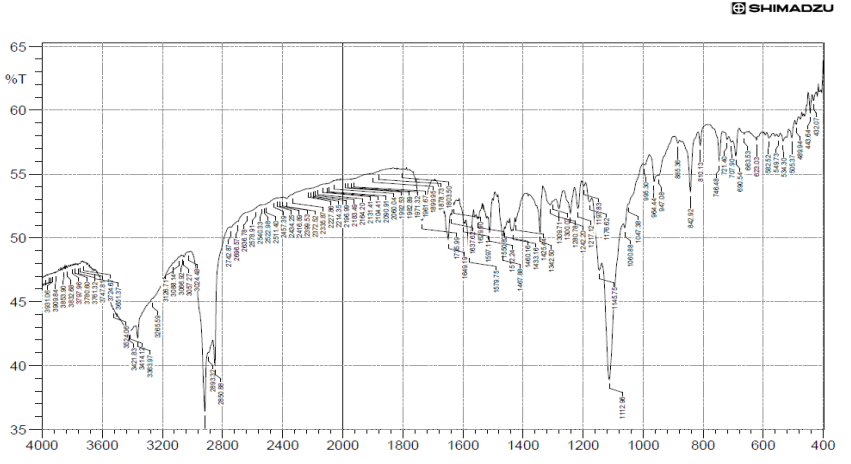

Fig. 7: FTIR spectrum of lovastatin pure drug

\section{FTIR Studies}

Fig. 7 indicates the appearance of lovastatin peak at $3,265.59 \mathrm{~cm}^{-1}$ for $\mathrm{C}=\mathrm{C}$ stretching, $3,524.06 \mathrm{~cm}^{-1}$ for $\mathrm{O}$-H stretching, $1,112.96 \mathrm{~cm}^{-1}$ for $\mathrm{C}-\mathrm{O}-\mathrm{C}$ stretching, $1,060.88 \mathrm{~cm}^{-1}$ for C-O stretching, and $1,309.71 \mathrm{~cm}^{-1}$ for $\mathrm{C}-\mathrm{H}$ bending, and $2,850.88 \mathrm{~cm}^{-1}$ for $\mathrm{C}-\mathrm{H}$ stretching. The same peaks were observed in physical mixture (Fig. 8) and optimized formulation (Fig. 9), which indicate no significant incompatibility between the components.

\section{X-Ray Diffraction Study}

The XRD spectrum of lovastatin indicates crystalline nature of the drug, while absence of these peaks indicates amorphous nature of SD15 formulation due to increased rate of drug release (Fig. 10). 


\section{SEM Studies}

SEM photographs (Figs 11 and 12) indicate the presence of smooth-surfaced and irregular crystals of drug, while the presence of drug in SD is not distinguished clearly. In SDs, the surface of drug appeared porous with wrinkled surface.

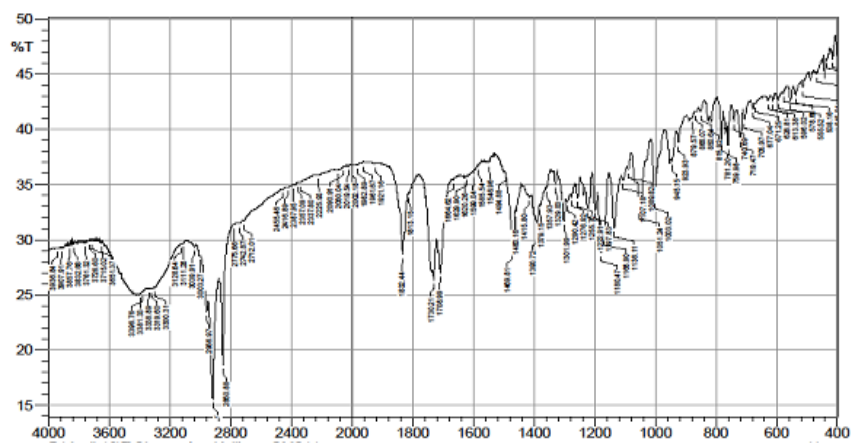

Fig. 8: FTIR spectrum of physical mixture

ФSHIMADZU

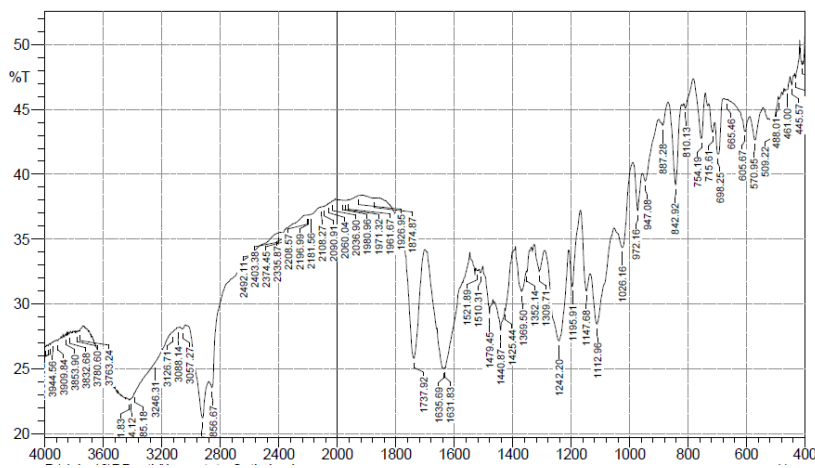

Fig. 9: FTIR of lovastatin optimized formulation SD15

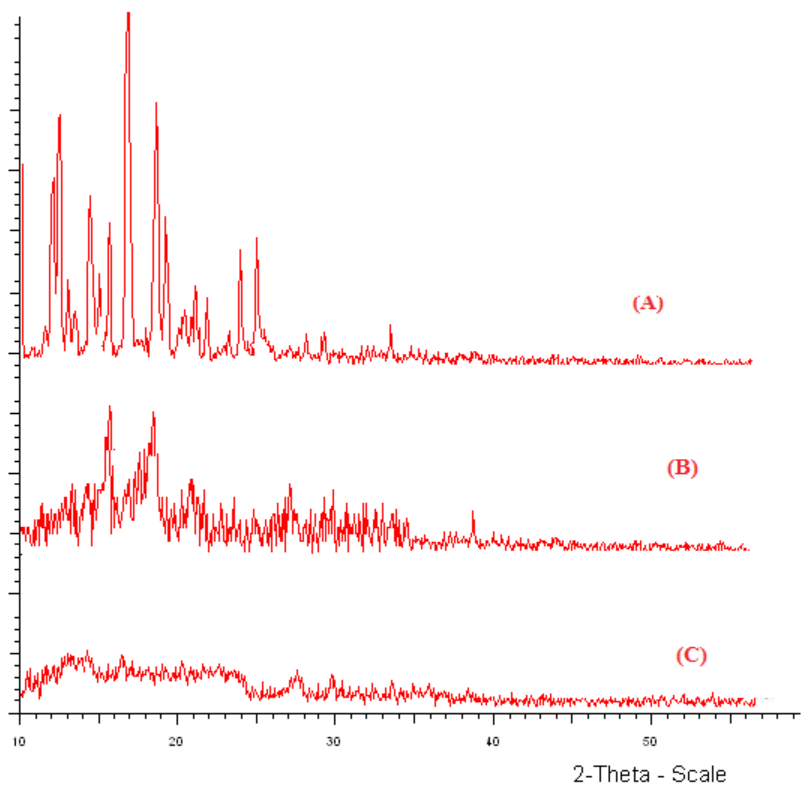

Fig. 10: XRD of (A) lovastatin, (B) physical mixture, and (C) optimized formulation SD15

\section{Stability Studies}

Optimized formulation (SD15) subjected to stability tests, as per ICH guidelines, indicated retention of all the properties of SD with no significant variations in drug content and drug release (Table 6).

\section{Formulation of Lovastatin Trilayer Tablets}

\section{Preformulation Studies}

The trilayer tablets prepared and characterized by various pre-compression micrometric analyses for the determination of flow properties. The bulk and tapped density of all tablet formulations vary between 0.59 to $0.62 \mathrm{~g} / \mathrm{cc}$. The angle of repose lies between $20^{\circ} .12 \pm 0.42$ and $26^{\circ} .23 \pm 0$, and Carr's index also range between $9.28 \pm 0.89$ and $13.67 \pm 0.96$. The formulation GF9 exhibited excellent flow properties (Table 7).

In vitro Drug Dissolution of Lovastatin Active Layer

From the results, the formulation F9 was decided as optimized formulation based on the highest drug release, i.e., $99.41 \pm 5.28 \%$ compared with other formulations as an active layer of the trilayer tablets (Fig. 13).

\section{Preparation of Trilayer Matrix Tablets of Lovastatin}

The trilayer matrix tablet was prepared according to the composition and method described in the methods.

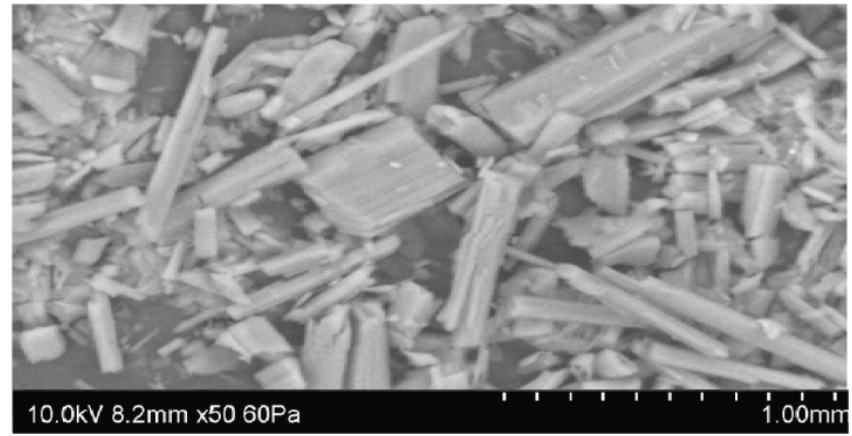

Fig. 11: SEM of lovastatin pure drug

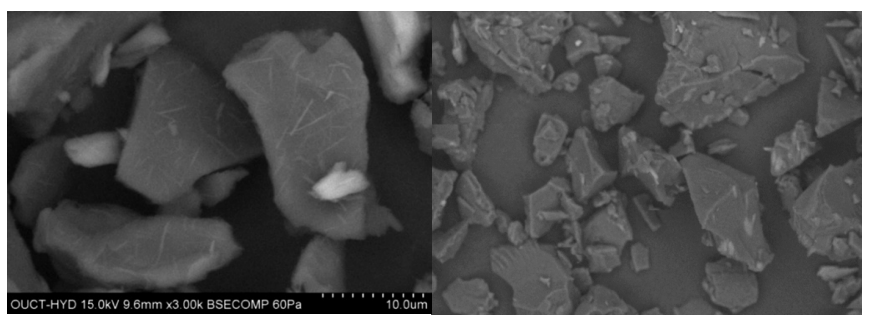

Fig. 12: SEM of lovastatin optimized formulation SD15

Table 6: Stability study of lovastatin SD (SD15)

\begin{tabular}{lll}
\hline Retest time & Drug content & In vitro drug release (\%) \\
0 days & 99.12 & 99.88 \\
30 days & 98.89 & 98.45 \\
60 days & 98.22 & 98.02 \\
90 days & 97.74 & 97.66 \\
\hline
\end{tabular}


Development of Trilayer Matrix Tablets of Lovastatin Solid Dispersions

Table 7: Powder flow property evaluation of lovastatin trilayer matrix tablets

\begin{tabular}{lllll}
\hline Formulation & Bulk density $(\mathrm{g} / \mathrm{cc})$ & Tapped density $(\mathrm{g} / \mathrm{cc})$ & Angle of repose $(\mathrm{o})$ & Carr's index \\
\hline AF9 & $0.59 \pm 0.05$ & $0.63 \pm 0.02$ & $26^{\circ} .23 \pm 0.51$ & $11.32 \pm 0.93$ \\
BF9 & $0.61 \pm 0.06$ & $0.64 \pm 0.02$ & $25^{\circ} .64 \pm 0.5$ & $12.29 \pm 0.94$ \\
CF9 & $0.6 \pm 0.06$ & $0.64 \pm 0.02$ & $25^{\circ} .78 \pm 0.5$ & $13.32 \pm 0.96$ \\
DF9 & $0.61 \pm 0.06$ & $0.65 \pm 0.03$ & $22^{\circ} .11 \pm 0.46$ & $11.67 \pm 0.93$ \\
EF9 & $0.62 \pm 0.06$ & $0.63 \pm 0.02$ & $24^{\circ} .32 \pm 0.49$ & $11.89 \pm 0.93$ \\
FF9 & $0.59 \pm 0.05$ & $0.64 \pm 0.02$ & $22^{\circ} .16 \pm 0.46$ & $12.45 \pm 0.94$ \\
GF9 & $0.58 \pm 0.05$ & $0.62 \pm 0.01$ & $20^{\circ} .12 \pm 0.42$ & $9.28 \pm 0.89$ \\
HF9 & $0.6 \pm 0.06$ & $0.67 \pm 0.04$ & $23^{\circ} .11 \pm 0.49$ & $13.67 \pm 0.96$ \\
\hline
\end{tabular}

$\mathrm{n}=3( \pm \mathrm{SD})$

Table 8: Physical evaluation of trilayer tablets

\begin{tabular}{lllll}
\hline Formulation & Hardness $\left(\mathrm{kg} / \mathrm{cm}^{2}\right)$ & Friability (\%) & Weight variation (mg) & Assay (\%) \\
\hline AF9 & 4 & 0.29 & $497 \pm 6.6$ & 95.66 \\
BF9 & 3 & 0.36 & $496 \pm 6.2$ & 94.69 \\
CF9 & 4 & 0.35 & $496 \pm 5.1$ & 96.32 \\
DF9 & 4 & 0.33 & $498 \pm 6.6$ & 95.09 \\
EF9 & 4 & 0.25 & $497 \pm 6.6$ & 94.12 \\
FF9 & 3 & 0.18 & $499 \pm 6.5$ & 96.32 \\
GF9 & 5 & 0.23 & $481 \pm 5.9$ & 99.63 \\
HF9 & 5 & 0.32 & $499 \pm 6.5$ & 95.16 \\
\hline
\end{tabular}

$\mathrm{n}=3( \pm \mathrm{SD})$

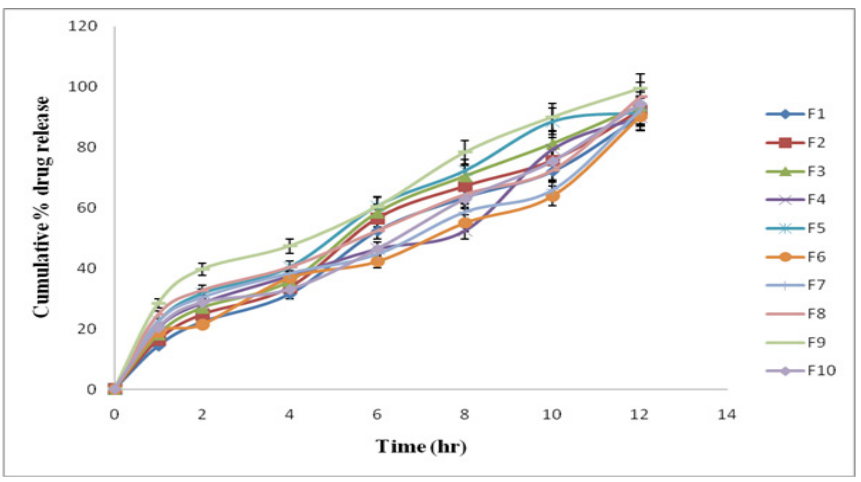

Fig. 13: In vitro dissolution profile of F1 to F10 lovastatin active layer formulations

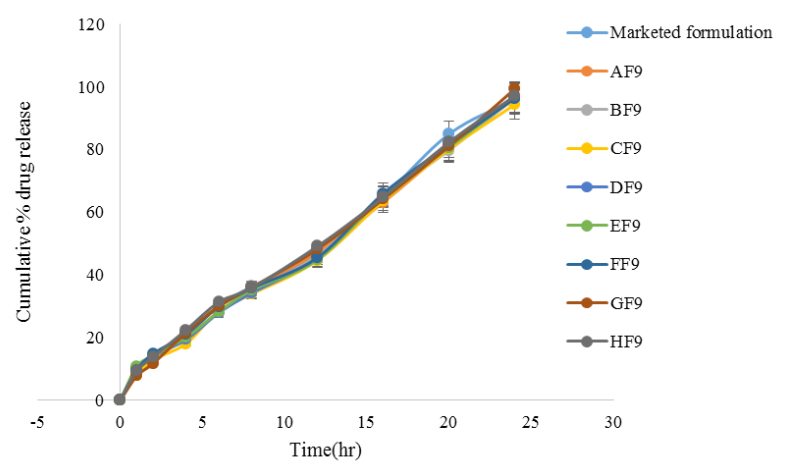

Fig. 14: Cumulative percentage drug release of lovastatin trilayer matrix tablets and marketed formulation

\section{Evaluation Parameters of Lovastatin Trilayer Matrix Tablets}

The physicochemical characteristic evaluation of the trilayer tablets indicates that the hardness of all the tablets varied from 3 to $5 \mathrm{~kg} / \mathrm{cm}^{2}$, while the friability is between 0.18 and $0.36 \%$. The percentage drug content of all formulations lies within 94.12 to 99.63\% (Table 8).

\section{In vitro Drug Dissolution of Lovastatin Trilayer Matrix} Tablets

All eight trilayer matrix tablets (AF9-HF9) formulations were evaluated for drug release indicated release of drug within 20 to 24 hours, with GF9 exhibiting maximum release of $99.36 \pm 5.33 \%$ within 24 hours (Fig. 14).

\section{Release Order Kinetics}

The release order kinetics data indicate the zero-order release with highest $\mathrm{R}^{2}=0.9957$ for GF9, better when compared to market extended-release formulation, which showed $\mathrm{R}^{2}$ value 0.9934 . All the formulations showed the best fit to the Higuchi model and Korsmeyer-Peppa's model, indicating diffusion and non-Fickian diffusion process of drug release (Figs 15 to 18; Table 9).

\section{Stability Studies of Lovastatin Trilayer Matrix Tablets}

Optimized formulation (GF9) subjected to stability tests, as per ICH guidelines, indicated retention of all the properties of lovastatin trilayer matrix tablets (GF9) with 
Chinthala Shanthi Priya et al.

Table 9: Release order kinetics of lovastatin trilayer matrix tablets

\begin{tabular}{llllllllll}
\hline & \multicolumn{1}{l}{$R^{2}$ values } & & & & & & \\
\cline { 2 - 9 } Release kinetics & Marketed formulation & AF9 & BF9 & CF9 & DF9 & EF9 & FF9 & GF9 & HF9 \\
\hline Zero-order & 0.9934 & 0.9955 & 0.9947 & 0.9951 & 0.9947 & 0.9936 & 0.9934 & 0.9957 & 0.9948 \\
First-order & 0.8628 & 0.832 & 0.8227 & 0.7978 & 0.8294 & 0.822 & 0.8406 & 0.7001 & 0.824 \\
Higuchi model & 0.9367 & 0.9409 & 0.9374 & 0.9267 & 0.9285 & 0.9302 & 0.9376 & 0.9378 & 0.9453 \\
Korsmeyer- & 0.8637 & 0.8737 & 0.8642 & 0.852 & 0.8478 & 0.8491 & 0.863 & 0.8707 & 0.8759 \\
Peppa's & & & & & & & & & \\
\hline
\end{tabular}

Table 10: Stability studies of lovastatin trilayer matrix tablets (GF9)

\begin{tabular}{lll}
\hline Retest time for optimized formulation (GF9) & Drug content (\%) & In vitro drug dissolution (\%) \\
\hline 0 days & $99.63 \pm 2.64$ & $99.36 \pm 2.72$ \\
30 days & $98.48 \pm 1.37$ & $98.88 \pm 1.78$ \\
60 days & $97.02 \pm 2.74$ & $98.32 \pm 4.93$ \\
120 days & $96.89 \pm 4.72$ & $97.22 \pm 1.74$ \\
180 days & $96.11 \pm 3.84$ & $97.06 \pm 2.84$ \\
\hline
\end{tabular}

$\mathrm{n}=\mathrm{SD} \pm 3$

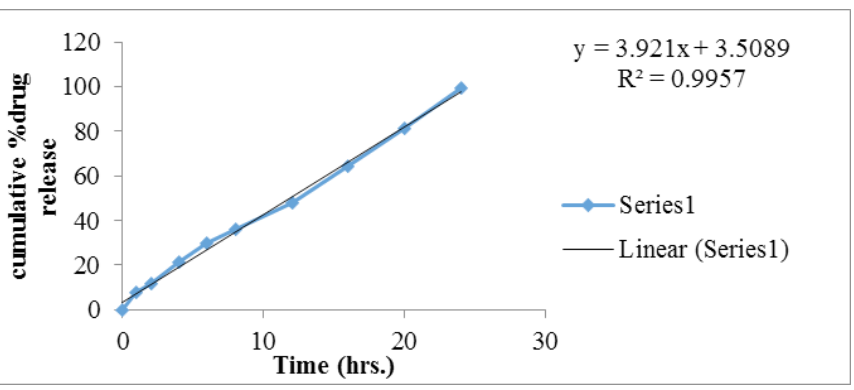

Fig. 15: Zero-order plot of optimized lovastatin trilayer matrix tablet GF9

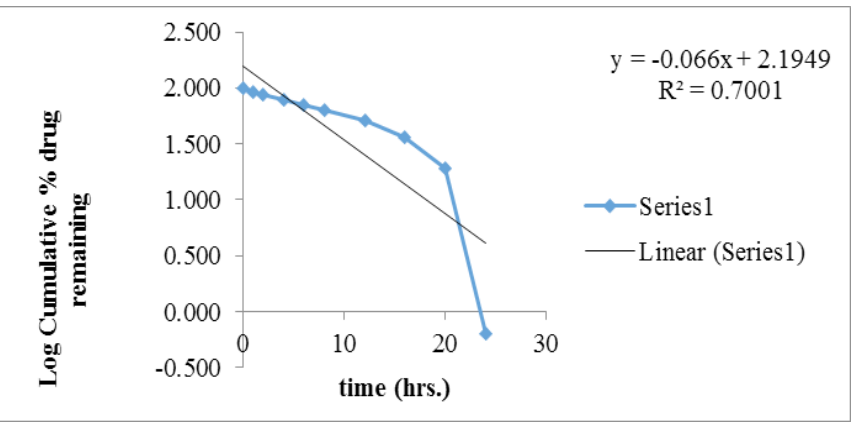

Fig. 16: First-order plot of optimized lovastatin trilayer matrix tablet GF9

no significant variations in uniformity in drug content and in vitro drug release (Table 10).

\section{DisCUSSION}

SD of lovastatin was prepared by solid evaporation method, and lovastatin SD formulation (SD15) containing drug, soluplus, and SLS exhibited higher dissolution rate with significant stability. This formulation is incorporated into the trilayer tablet matrix by the compression method. The trilayer matrix formulation GF9 exhibited excellent flow properties with maximum drug release of $99.36 \%$ in 24 hours. The release kinetics for all formulations followed

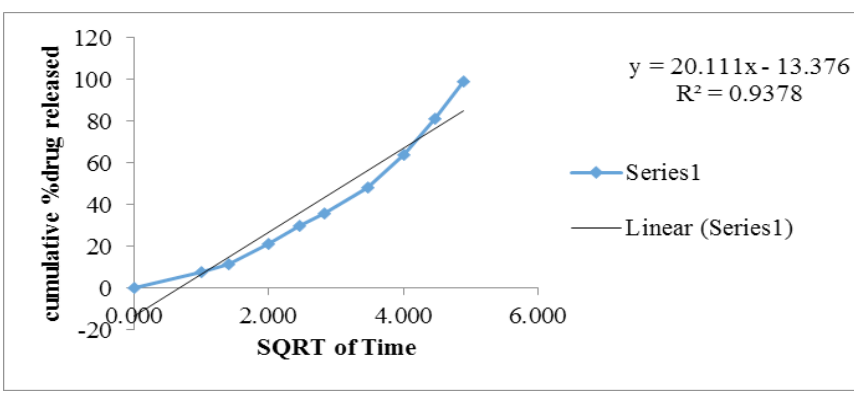

Fig. 17: Higuchi plot of optimized lovastatin trilayer matrix tablet GF9

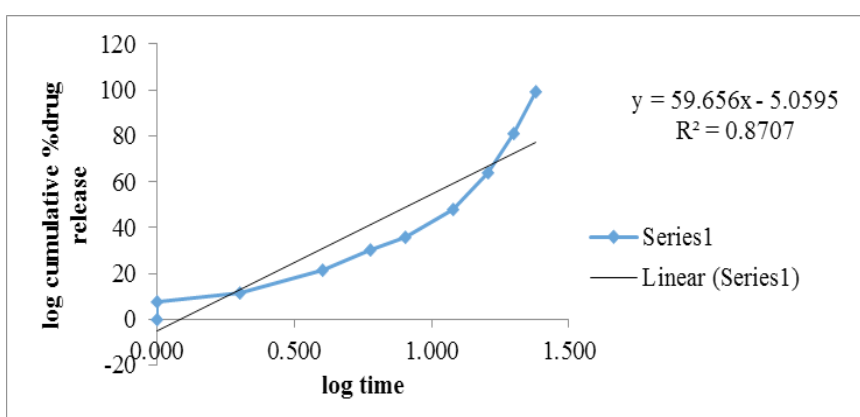

Fig. 18: Korsmeyer-Peppa's plot of optimized lovastatin trilayer matrix tablet GF9

zero-order release kinetics and showed correlation coefficient $\left(R^{2}\right)$ in the range of 0.9934 to 0.9957 for various formulations with the highest for GF9. All the formulations showed the best fit to the Higuchi model and Korsmeyer-Peppa's model, confirming to be diffusion assisted mechanism with non-Fickian drug release. The drug compatibility analysis by FTIR indicates no interaction between the lovastatin and excipients. The SEM results indicate amorphous structure for trilayer tablets indicative of more bioavailability and sustainable release of the drug. Thus, one may conclude that SD included trilayer matrix formulation of lovastatin have potential for consideration for drug delivery by enhancing solubility 
and dissolution rate and sustaining the drug release to 24 hours.

\section{REFERENCES}

1. Mallick Sahu A, Paul K. Dissolution behaviour of Nalidixic acid solid dispersions using water soluble solid dispersions carriers. Acta Pol Pharm Drug Res. 2004;60(1):21-30.

2. Sammour OA, Zidan AS, Hammad MA, Megrab NA. Formulation and optimization of mouth dissolve tablets containing rofecoxib solid dispersion. AAPS Pharm Sci Tech. 2006;7(2):162-169.

3. Shin SC, Kim J. Physicochemical Characterization of solid dispersion of Furosemide with TPGS. Int J Pharm. 2003;251:79-84.

4. Craig DQM. The mechanisms of Drug Release from solid dispersions in water-soluble polymers. Int J Pharm. 2002;231:131-144.

5. De Waard H, Hinrichs WLJ, Frijlink HW. A novel bottom-up process to produce drug nano crystals controlled crystallization during freeze-drying. J Con Rel. 2008;128:179-183.

6. Higuchi T, Connoras K. Phase-solubility techniques. Adv Anal Chem Instrum. 1965;4:117-212.

7. Swathi P, Anand YK. Formulation and Evaluation of Ritonavir solid dispersions. Int J Res Dev Pharm L Sci. 2017;6(2):2522-2529.

8. Mohammadi H, Hemanath KV. Formulation and evaluation of solid dispersion incorporated fast disintegrating tablets of tenoxicam using design of experiment. Int J Pharm Sci Drug Res. 2019;11(1):35-44.

9. Vanshiv SD, Rao MRP, Sonar GS. Physicochemical characterization and in vitro dissolution of domperidone by solid dispersion technique. Ind J Pharm Edu Res. 2009;43(1):86-90.

10. Subhash K, Bidkar SJ, Dama GY. Formulation and evaluation of ciprofloxacin solid dispersion controlled release floating capsules for solubility improvement. Indian J Pharm Biol Res. 2017;5(3):7-16.

11. Batra V, Shirolkar VS, Mahaparale PR. Solubility and dissolution enhancement of glipizide by solid dispersion technique. Ind J Pharm Edu Res. 2008;42(4):373-378.

12. Yadav B, Tanwar YS. Development, characterization and in vitro evaluation of flurbiprofen solid dispersions using polyethylene glycols as carrier. J App Pharm Sci. 2016;6(04):60-66.

13. Mohammadi G, Barzegar-Jalali A, Khosro A. Development and characterization of solid dispersion for dissolution improvement of furosemide by co grinding method. Adv Pharm Bull. 2014;4(4):391-399.
14. Soliman MS, Khan MA. Preparation and in vitro characterization of a semi-solid dispersion of flurbiprofen with Gelucire44/14 and Labrasol. Pharmazie. 2005;60(4):288-293.

15. Etman MA, Nada AH. Hydrotropic and cosolvent solubilization of indomethacin. Acta Pharm. 1999;49:291-298.

16. Reddy G, Vidyadhara S, Babu J, Rlc Sasidhar, Ramu A. Formulation and evaluation of lovastatin solid dispersions with pregelatinized starch as newer super disintegrant. J of Pharm Res. 2012;11:38.

17. Afroze A, Sabya SD, Afzal H, Abdul F. Formulation and evaluation of solid dispersion and inclusion complex of poorly aqueous soluble diacerein. JOJ Material Sci. 2018;5(1):555-651.

18. Saravanan M, Natraj KS, Ganesh KS. The effect of tablet formulation and hardness on in vitro release of cephalexin from Eudragit L100 based extended release tablets. Biol Pharm Bull. 2002;25:4541-4545.

19. Afrasim M, Shivakua HG. Formulation of sustained-release diltiazem matrix tablets using hydrophilic gum blends. Trop J of Pharm Res. 2010;9:283-291.

20. Thenge R, Mahajan SS, Mahajan NM, Adhao V, Ajmire PV. Formulation and evaluation of buccoadhesive drug delivery system for lovastatin. JDDT. 2019.

21. Anton S, Muthu AK, Wagh BP, Manavalan R. Formulation development and evaluation of ondansetron hydrochloride sustained release matrix tablets. J Pharm Sci and Res. 2009;1:48-54.

22. Saravanan M, Natraj KS, Ganesh KS. Hydroxypropyl methyl cellulose-based cephalexin extended release tablets: influence of tablet formulation, hardness and storage on in vivo release kinetics. Chem Pharm Bull. 2003;51:978-983.

23. Bhupendra G, Prajapati, Patel KR. Design and in vitro evaluation of novel nicorandil sustained release matrix tablets based on combination of hydrophilic and hydrophobic matrix system. Int J of Pharm Sci Rev and Res. 2010;1(1):33-38.

24. Reddy KR, Mutalik S, Reddy S. Once-daily sustained release matrix tablets of nicorandrail, formulation and in vitro evaluation. AAPS Pharm Sci Tech. 2003;4:61.

25. Siepmann J, Kranz H, Bodmeier R, Peppas NA. HPMC-matrices for controlled drug delivery: a new model combining diffusion, swelling, and dissolution mechanisms and predicting the release kinetics. Pharm Res. 1999;16:1748-1756.

26. Ganesh R, Suresh K, Jawahar, Senthil V, Nagasamy D. Preparation and evaluation of sustained release matrix tablet of diclofenac sodium using natural polymer. J of Pharm Sci and Res. 2010;2:360-368. 